\title{
Composición de la leche de vacas Holstein suplementadas con caña de azúcar integral y saccharina rústica enriquecida
}

\author{
Córdova-Izquierdo, A.'; Lara Torres, J.A.'2; \\ Amaro Gutiérrez, R. ${ }^{2}$; Peña Betancourt, S.D. ${ }^{1}$; Xolalpa Campos, V.M. ${ }^{1}$ \\ ${ }^{1}$ Departamento de Producción Agrícola y Animal, Universidad Autónoma Metropolitana, Unidad Xochimilco, \\ Calz. Del Hueso 1100, Col. Villa Quietud, C.P. 04960, México DF. ${ }^{2}$ Práctica privada. \\ E-mail: acordova@correo.xoc.uam.mx.
}

\begin{abstract}
Resumen
Córdova-Izquierdo, A.; Lara Torres, J.A.; Amaro Gutiérrez, R.; Peña Betancourt, S.D.; Xolalpa Campos, V.M.: Composición de la leche de vacas Holstein suplementadas con caña de azúcar integral y saccharina rústica enriquecida. Rev. vet. 21: 1, 66-68, 2010. La composición de la leche asume importancia por tratarse de un alimento de gran valor nutritivo y alto consumo humano. El objetivo de este trabajo fue evaluar el efecto de dos tipos de suplementos a base de caña de azúcar sobre la composición de la leche de vacas Holstein. Se utilizaron dos grupos de diez vacas cada uno, las cuales fueron suplementadas durante seis meses con saccharina rústica enriquecida (grupo A) y caña de azúcar integral (grupo B). Bimestralmente se efectuaron análisis químicos proximales de los alimentos y pruebas de calidad láctea. Los niveles de proteína bruta y fibra cruda de la saccharina empleada (14 y $38,7 \%$ respectivamente) se aproximaronn a los reportados en otros trabajos (13,05 y $34,58 \%$ respectivamente). Para la caña de azúcar los valores de proteína bruta $(6,5 \%)$ resultaron más altos que los comunicados por otros autores $(2,6-4,7 \%)$ pero los de fibra cruda fueron más bajos $(32,3 \%)$ que los citados por la bibliografía $(36,1-48,1 \%)$. El promedio de los análisis de leche reveló $3,4 \%$ de grasa, $3,1 \%$ de proteínas y $5 \%$ de lactosa (grupo A) y $3,2 \%$ de grasa, $3,1 \%$ de proteínas y $4,8 \%$ de lactosa (grupo B). Se concluye que la suplementación con saccharina rústica enriquecida aporta mayor cantidad de nutrientes que la caña de azúcar integral y genera mejores índices en la composición de la leche.
\end{abstract}

Palabras clave: vaca lechera, suplementación, caña de azúcar, composición láctea.

\begin{abstract}
Córdova-Izquierdo, A.; Lara Torres, J.A.; Amaro Gutiérrez, R.; Peña Betancourt, S.D.; Xolalpa Campos, V.M.: Composition of milk from Holstein cows supplemented with integral sugar cane and enriched rustic saccharina. Rev. vet. 21: 1, 66-68, 2010. Composition of milk assumes importance because is a food of high nutritional value and high human consumption. The aim of this study was to evaluate the effect of two types of supplements based on sugar cane on the composition of milk from Holstein cows. Two groups of ten cows each, which were supplemented for six months with enriched rustic saccharina (group A) and whole sugarcane (group B), were used. Twice-a-month, chemical analysis of diets as well as milk quality tests were carried out. Levels of crude protein and crude fiber of saccharina used in this assay (14 and 38.7\% respectively) were close to those reported in other studies (13.05 and $34.58 \%$ respectively). Sugar cane crude protein values $(6.5 \%)$ were higher than those reported by other authors ( 2.6 to $4.7 \%$ ), whereas crude fiber values were lower $(32.3 \%)$ than those previously reported (from 36.1 to $48.1 \%$ ). The average milk test revealed $3.4 \%$ fat, $3.1 \%$ protein and $5 \%$ lactose (group A) and 3.2\% fat, 3.1\% protein and $4.8 \%$ lactose (group B). It can be concluded that supplementation with enriched rustic saccharina provides more nutrients than whole sugarcane and produces better rates in milk composition.
\end{abstract}

Key words: dairy cow, supplementation, sugar cane, milk composition. 


\section{INTRODUCCIÓN}

La calidad de la leche asume actualmente una importante dimensión ante la demanda de los consumidores por un producto más seguro, con una más larga vida de anaquel y un más alto valor nutritivo. La calidad está determinada por aspectos atinentes a la composición e higiene del producto; la composición de la leche está influenciada por factores como alimentación, manejo, genética y otros ${ }^{5}$.

La caña de azúcar es un cultivo de gran importancia a nivel mundial debido a la alta captación económica que reviste. Hasta el año 2001, México se ubicó a nivel mundial entre los quince primeros países productores ${ }^{4}$. Es un cultivo ampliamente difundido en México, existen más de 15 regiones cañeras distribuidas en la costa del Pacífico, Área Central, Golfo de México y Área Caribeña en la Península de Yucatán.

Con la caña de azúcar es posible intensificar la ganadería, logrando una mayor producción por unidad de superficie al incrementar la carga animal. Se deberían desarrollar sistemas más apropiados para el uso de la caña de azúcar en la alimentación de bovinos porque ella y sus subproductos tienen mucho que aportar a la producción animal. La caña de azúcar es un cultivo de alto rendimiento forrajero, con el cual se pueden alcanzar hasta $200 \mathrm{tn} /$ ha/año de caña integral, tallo y hojas ${ }^{7}$.

Cabe destacar este cultivo, cuya ventaja radica en aprovechar la intensa radiación solar y la alta temperatura a lo largo del año que ofrecen las zonas tropicales, constituye además un recurso que ofrece variedad de subproductos para la alimentación animal; tiene características competitivas frente a diferentes cultivos forrajeros en distintas épocas (especialmente sequía) por la cantidad de materia seca que produce y los carbohidratos solubles que acumula con la edad ${ }^{8}$.

Una alternativa para mejorar la calidad de la caña de azúcar es procesarla para obtener saccharina, subproducto obtenido por fermentación en fase sólida de los tallos de la caña (molidos), desprovistos de las hojas. Esta fermentación microbiana permite obtener un producto de mayor calidad, por el nivel y tipo de proteínas que se producen durante el proceso en la biomasa proteica de microorganismos que se desarrollan a partir de la microflora epifítica presente en la caña de azúcar, los que se nutren de los azúcares presentes y cuyo desarrollo se favorece con el aporte de pequeñas cantidades de urea y sales minerales $(1,5$ y $0,5 \%$ en base fresca, respectivamente) ${ }^{8}$.

De acuerdo al procedimiento empleado para la fermentación y secado de la caña durante la elaboración de este producto, se obtienen tres tipos de saccharina: industrial, semi-industrial y rústica. La elaboración de esta última puede realizarse de manera ventajosa en el propio predio ganadero, ya que no requiere equipamiento sofisticado. Para una mayor eficiencia del proceso, la caña troceada finamente debe disponerse en una capa de un grosor de $10-15 \mathrm{~cm}$ y dejarse fermentar durante
Tabla 1. Composición de los suplementados suministrados (\%).

\begin{tabular}{lccccc}
\hline suplemento & MS & EE & CT & PB & FC \\
\hline saccharina & 82 & 2,4 & 4,8 & 14 & 38,7 \\
caña de azúcar & 76 & 1,7 & 2,4 & 6,5 & 32,3 \\
\hline
\end{tabular}

MS: materia seca, EE: extracto etéreo, CT: cenizas totales, PB: proteína bruta, FC: fibra cruda.

24 horas, teniendo en cuenta que la prolongación de dicho lapso no se traduce en una mayor síntesis ${ }^{8}$.

El objetivo de este trabajo fue comparar el efecto de la suplementación de vacas lecheras con sacharina rústica enriquecida versus caña de azúcar integral, sobre la composición química de la leche.

\section{MATERIAL Y MÉTODOS}

El estudio se realizó en una unidad de producción animal de ganado lechero ubicada en el municipio de Zacatepec, Estado de Morelos, México. Se dispuso de dos grupos experimentales (A y B) de vacas Holstein en producción. El grupo $A(n=10)$ fue suplementado durante 6 meses con saccharina rústica enriquecida con urea, sulfato de amonio, sales minerales y pulido de arroz, en tanto que el grupo $B(n=10)$ recibió caña de azúcar integral (hojas y tallos picados) durante el mismo período. La relación forraje-concentrado fue de $70-30 \%$ respectivamente.

Cada dos meses se efectuaron análisis químicos proximales de ambos tipos de suplemento, utilizando muestras obtenidas de forma aleatoria para determinar los contenidos de materia seca, extracto etéreo, cenizas totales, proteína bruta y fibra cruda, realizados acorde a las instrucciones recomendadas por la $\mathrm{AOAC}^{1}$.

Bimestralmente se colectaron cinco muestras de leche de cada grupo de manera aleatoria, determinando los indicadores convencionales de calidad de leche por medio de un analizador fisicoquímico Milkoscan. Las muestras de leche fueron refrigeradas hasta su llegada al laboratorio, donde se efectuaron determinaciones de grasa, proteínas, lactosa, sólidos totales y sólidos no grasos. Los resultados obtenidos fueron analizados mediante estadística descriptiva convencional.

\section{RESULTADOS Y DISCUSIÓN}

La Tabla 1 muestra la composición proximal de los suplementos suministrados a las vacas lecheras (promedios de tres muestreos). De su análisis surge que la saccharina rústica enriquecida superó a la caña de azúcar integral en sus contenidos de grasa, cenizas, proteínas y fibra. La diferencia más marcada entre ambos suplementos fue la de proteínas, las cuales resultaron considerablemente mayores en saccharina.

Los valores nutricionales aquí obtenidos para saccharina, especialmente para proteínas y fibra, concuerdan con los resultados obtenidos por investigadores co- 
Tabla 2. Composición de la leche (\%) según el suplemento dietario.

\begin{tabular}{lccccc}
\hline suplemento & grasa & proteínas & lactosa & sólidos totales & sólidos no grasos \\
\hline saccharina & 3,4 & 3,1 & 5,0 & 12,0 & 8,8 \\
caña de azúcar & 3,2 & 3,0 & 4,8 & 11,7 & 8,5 \\
\hline
\end{tabular}

lombianos para el mismo alimento, quienes reportaron cifras de $13.05 \%$ de proteína bruta y $34.58 \%$ de fibra cruda ${ }^{8}$. En cambio, los valores aquí encontrados en la caña de azúcar fueron más altos para proteína bruta y más bajos para fibra cruda que los publicados por un autor venezolano, de $2,6-4,7 \%$ y $36,1-48,1 \%$ respectivamente ${ }^{6}$.

En la Tabla 2 se presentan los promedios de los resultados de los análisis lácteos practicados en las muestras provenientes de los grupos A y B. Todos los valores fueron superiores en la leche de los animales suplementados con saccharina, con relación a los alimentados con caña de azúcar. Teniendo en cuenta que la composición de la leche debe ser una prioridad en las unidades de producción por tratarse de un alimento de gran importancia al constituir una de las principales fuentes de suministro de proteína animal para la población, se desprende que las vacas sometidas a la dieta que contenía saccharina revelaron proporciones similares a los rangos recomendados por otros investigadores, de $3,8-3,5 \%$ de grasa, $3,2 \%$ de proteína y $4,7-5,3 \%$ de lactosa ${ }^{2,3}$.

Hembras Holstein suplementadas a partir de los 12 meses de edad con saccharina (50\% del concentrado) revelaron un más rápido crecimiento, a la par de exhibir aumentos del porcentaje de grasa y disminución del porcentaje de proteínas en la leche ${ }^{8}$. La inclusión de $70 \%$ de saccharina industrial en los piensos de vacas lecheras permitió obtener producciones de leche cercanos al $85 \%$ del potencial productivo de los animales, así como la posibilidad de prescindir de una proporción considerable de cereales, sin afectar los componentes de la leche (grasa, sólidos totales y sólidos no grasos), que se mantuvieron en los rangos normales de 3,9; 8,8 y $12,7 \%$ respectivamente, sin diferir de los obtenidos a través de la suplementación con piensos comerciales a base de cereales ${ }^{8}$.

Se concluye que la suplementación con saccharina rústica enriquecida aporta mayor cantidad de nutrientes que la caña de azúcar integral y genera mejores índices en la composición de la leche de vacas Holstein.

\section{REFERENCIAS}

1. Association of Official Analytical Chemists (AOAC). 1995. Official methods of analysis (Cunnif PA, ed.), AOAC Internat, Arlington, $2000 \mathrm{p}$.

2. Calderón A, García F, Martínez G. 2006. Indicadores de calidad de leches crudas en diferentes regiones de Colombia. Rev Med Vet Zoot (Colombia) 11: 725-737.

3. Hernández CJ. 2002. Parámetros internacionales de la calidad de la leche. Memorias XIV Sem Intern Agron FAZUJED, México, p. 101-104.

4. Jiménez CA, Vargas TV, Aguirre BM, Rodríguez CD. 2004. Aptitud agroecológica para el cultivo de la caña de azúcar en el sur de Tamaulipas, México. Investig Geograf (Boletín del Instituto de Geografía, UNAM, México), 53: $58-74$.

5. Saltijeral OJ, Córdova IA. 2001. Calidad de la leche y seguridad de los alimentos lácteos. Memorias I Semin Intern Reprod Animal Prod Leche y Carne, Xochimilco (México), p. 46-53.

6. Urdaneta J. 2005. La caña de azúcar: una opción para el ganadero. Manual de ganadería de doble propósito, $\mathrm{Ed}$ Astro Data (Caracas), p. 231-235.

7. Vassallo M. 2007. Caña de azúcar, mandioca y batata para forraje en la producción intensiva de carne. On line: $w w w$. produccion-animal.com.ar, p. 1-3

8. Vivas NJ, Carvajal J. 2004. Saccharina rústica: una aplicación biotecnológica para la alimentación animal. Rev Biotecnol Agropec (Popayán, Colombia) 2: 43-48. 